\title{
Evaluation of a pharmacogenetic-based warfarin dosing algorithm in patients with low time in therapeutic range - study protocol for a randomized controlled trial
}

Leiliane Rodrigues Marcatto', Luciana Sacilotto², Carolina Tosin Bueno', Mirella Facin², Celia Maria Cassaro Strunz ${ }^{3}$, Francisco Carlos Costa Darrieux ${ }^{2}$, Maurício Ibrahim Scanavacca ${ }^{2}$, Jose Eduardo Krieger ${ }^{1}$, Alexandre Costa Pereira ${ }^{1 *}$ and Paulo Caleb Junior Lima Santos ${ }^{1 *}$

\begin{abstract}
Background: Time in therapeutic range (TTR) is a measurement of quality of warfarin therapy and lower TTR values $(<50 \%)$ are associated with greater risk of thromboembolic and bleeding events. Recently, we developed a pharmacogenetic-based warfarin dosing algorithm specifically calibrated for a Brazilian patient sample. The aims of this study are: to evaluate the impact of a genetic-based algorithm, compared to traditional anticoagulation, in the time to achieve the therapeutic target and in TTR percentage; and to assess the cost-effectiveness of genotype-guided warfarin dosing in a specific cohort of patients with low TTR (<50\%) from a tertiary cardiovascular hospital.

Methods/design: This study is a randomized controlled trial in patients $(n=300)$ with atrial fibrillation with $T T R<50 \%$, based on the last three INR values. At the first consultation, patients will be randomized into two groups: TA group (traditional anticoagulation) and PA group (pharmacogenetic anticoagulation). For the first group, the physician will adjust the dose according to current INR value and, for the second group, a pharmacogenetic algorithm will be used. At the second, third, fourth and fifth consultations (with an interval of 7 days each) INR will be measured and, if necessary, the dose will be adjusted based on guidelines. Afterwards, patients who are INR stable will begin measuring their INR in 30 day intervals; if the patient's INR is not stable, the patient will return in 7 days for a new measurement of the INR. Outcomes measures will include the time to achieve the therapeutic target and the percentage of TTR at 4 and 12 weeks. In addition, as a secondary end-point, pharmacoeconomic analysis will be carried out. Ethical approval was granted by the Ethics Committee for Medical Research on Human Beings of the Clinical Hospital of the University of São Paulo Medical School.

Discussion: This randomized study will include patients with low TTR and it will evaluate whether a population-specific genetic algorithm might be more effective than traditional anticoagulation for a selected group of poorly anticoagulated patients.
\end{abstract}

Trial registration: ClinicalTrials.gov, NCT02592980. Registered on 29 October 2015.

Keywords: Warfarin, Algorithm, Pharmacogenetic, Pharmacoeconomy, Polymorphisms

\footnotetext{
* Correspondence: alexandre.pereira@incor.usp.br; pacaleb@usp.br

1 Laboratory of Genetics and Molecular Cardiology, Heart Institute (InCor),

University of São Paulo Medical School, Av. Dr. Eneas de Carvalho Aguiar, 44

Cerqueira Cesar, São Paulo, SP CEP 05403-000, Brazil

Full list of author information is available at the end of the article
} 


\section{Background}

Warfarin is a vitamin $\mathrm{K}$ antagonist and is the most widely prescribed oral anticoagulant agent worldwide [1]. It is used to prevent morbidity and mortality due to thromboembolism and, for this reason, it is very important to achieve an optimal anticoagulant therapy [2]. Furthermore, warfarin has a narrow therapeutic range and, consequently, patients usually have difficultly achieving and maintaining the therapeutic target [3-5].

Time in therapeutic range (TTR) is a measure of the quality of warfarin therapy, i.e., the percentage of time a patient's INR (international normalized ratio) is within the desired treatment target. Lower TTR values $(<50 \%)$ are associated with greater risk of thromboembolic and bleeding events; while higher TTR values (>65\%) are associated with therapeutic benefits $[6,7]$. Some studies identified factors that can affect TTR, such as the use of age, gender, race, and concomitant medications for predicting one's ideal dosage [8-15]. In this scenario, some studies have assessed the impact of pharmacogenetic algorithms to guide the beginning of treatment. Pirmohamed et. al followed-up, for 12 weeks, patients who were recruited in the United Kingdom and Sweden. They used a slightly modified version of the International Warfarin Pharmacogenetics Consortium algorithm for predicting maintenance doses. They identified that the mean percentage of TTR was higher in the genotype-guided group (67.4\%) compared with the control group (60.3\%, $p<0.001)$ [16]. Verhoef et al studied patients taking acenocoumarol or phenprocoumon recruited in the Netherlands and Greece. They used an algorithm developed by EU-PACT group for phenprocoumon and acenocoumarol drugs [17]. They identified that genotype-guided dosing did not improve the TTR during the first 12 weeks after the initiation of therapy ( 61.6 and $60.2 \%, p=0.52)$. However, they identified different TTR during the first 4 weeks after the initiation of treatment comparing pharmacogenetic and control groups (52.8 and 47.5\%, $p=0.02$ ) [18]. Kimmel et al, studied patients from 18 clinical centers in the United States. They used an algorithm developed by the COAG group [19]. The authors concluded that genotype-guided dosing of warfarin did not improve anticoagulation control during the first 4 weeks of therapy [20].

Recently, we developed a pharmacogenetic-based warfarin dosing algorithm specifically tailored for Brazilian individuals, a highly admixed population. It was shown to be more accurate than internationally developed algorithms for individuals from the Brazilian population [21]. Likewise, some other studies have shown that pharmacogenetic algorithms could be more accurate when developed and applied on specific populations [22-24].

Furthermore, studies showed the ability to improve TTR, compared with traditional anticoagulation, using strategies such as educational intervention, point-of-care testing, and the use of family practice clinics [25-27]. In this context, there is no data in the literature on the specific testing of a pharmacogenetic algorithm in patients with low TTR $(<50 \%)$. In addition, cost-effectiveness evaluations for this approach are scarce and a positive finding for a pharmacogenetic approach could be very useful in a program of individualized anticoagulation therapy [28-30].

Thus, the aims of this study are: to evaluate the impact of a genetic-based, population-specific, algorithm, compared to traditional anticoagulation, in the time to achieve the therapeutic target and in the percentage of TTR at 4 and 12 weeks; and to assess the cost-effectiveness of genotype-guided warfarin dosing in a specific cohort of patients with low TTR $(<50 \%)$ from a tertiary cardiovascular hospital.

\section{Methods}

\section{Trial design}

We will recruit 300 patients with low TTR $(<50 \%)$ from the Heart Institute- Clinical Hospital-University of São Paulo Medical School (InCor- HCFMUSP).

The study protocol was approved by the Ethics Committee for Medical Research on Human Beings of the Clinical Hospital of the University of São Paulo Medical School (SDC 4033/14/013). Signed informed consent will be obtained from all participants.

Figure 1 shows the study design. Physicians will select the eligible patients according to the described criteria. At the first consultation, the pharmacist will explain the study and, if the patient accepts to participate, he or she will then sign the term. Patients will be randomized into two groups: TA group (traditional anticoagulation) and PA group (pharmacogenetic anticoagulation). Randomization will be considered protocol starting date. Pharmacists will apply questionnaires and collect blood samples for DNA extraction and measure creatinine, AST and ALT.

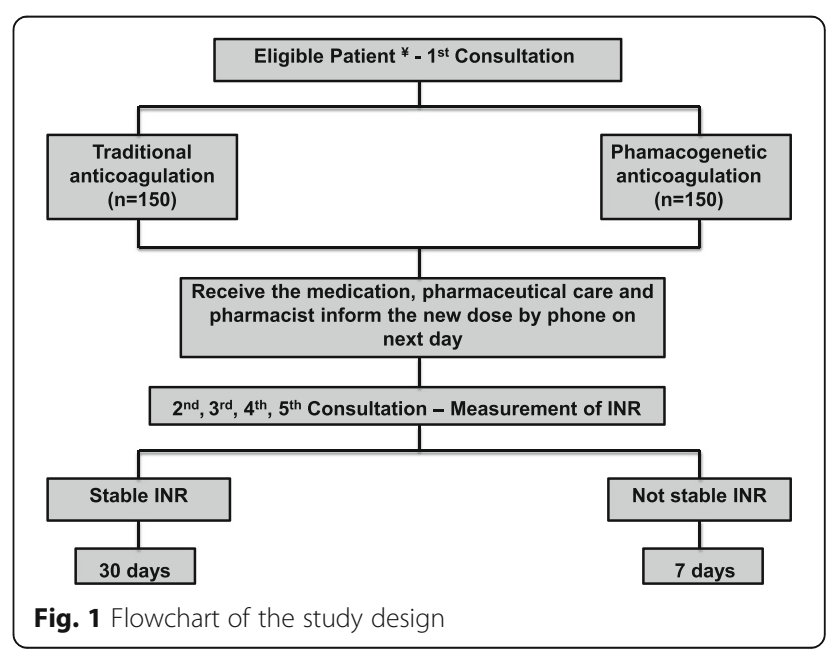


For the TA group, the physician will adjust the dose according to the current INR value based on current guidelines [31, 32]. For the PA group, the dose will be prescribed based on data from each patient applied in a pharmacogenetic algorithm. In some cases, used algorithm may provide a counter-intuitive dose, i.e., a dose that is not adequate for adjusting the current patient' INR (for example, a higher dose for a patient that already has a high INR). In these cases, the physician will adjust the dose following clinical criteria based on published guidelines and these patients will be kept on PA group [3, 33]. Patients of both groups will receive the medication and receive the pharmaceutical care. On the day after randomization, the pharmacist will inform, by phone, the new weekly dose prescribed for patients of both groups.

At the second (7 days), third (14 days), fourth (21 days), and fifth (28 days) consultations (with an interval of 7 days each), warfarin dosage will be adjusted, if necessary, based on current guidelines [31, 32].

After the fifth consultation, if the patient's INR is within therapeutic target, the next measurement will be made after 30 days. If the patient's INR is not in the therapeutic target, the warfarin dose adjustment will be made and the next INR measurement will be made after 7 days. The main outcomes will be the time to achieve the therapeutic target and the percentage of TTR at 4 and 12 weeks. We will measure the INR of all patients at the 12th week, independently of the value of INR before of this endpoint.

\section{Participants}

Only patients with atrial fibrillation, above 18 years, and with TTR $<50 \%$ based on the last three values of INR will be included in this study. Patients will be excluded if they have reached a stable dose of warfarin, liver dysfunction, alcoholism, use of another anticoagulant, use of chemotherapy, if they changed the dose of amiodarone 1 week before or if they do not meet the inclusion criteria.

\section{Interventions}

For the TA group, the physician will adjust the dose according to the current INR value based on current guidelines [31, 32] and using an EP mobile tool for dividing the weekly dose in the days with the availability of tablets [34].

Patients with INR values $<1.8$ or $>3.2$ will undergo dose adjustment. For patients with an INR value from 1.8 to $<2.0$ or from $>3.0$ to 3.2 , warfarin dose will be maintained and INR tests will continue to be made every 7 days. Then, if the patient continues to demonstrate values from 1.8 to $<2.0$ or from $>3.0$ to 3.2 , warfarin dose will be changed. At each patient consultation, the pharmacist will check the drug adherence counting pills and adverse events using patient self-reporting information. The average weekly warfarin dose will be changed according to patient's INR value: $\leq 1.5$, increase by $20 \%$; $>1.5-<2.0$, increase by $5 \%$; $>3.0-3.5$, decrease by $5 \%$; $>3.5-<6.0$, hold 1 dose, decrease by $15 \%$; $\geq 6.0$, hold warfarin and consider vitamin $\mathrm{K}$ based on guidelines [31, 32].

For the PA group, the dose will be prescribed based on data from each patient applied in a pharmacogenetic algorithm for the first consultation, after will adjust the dose based on guidelines and using the EP mobile [21].

\section{Outcomes}

We will use the time to achieve the therapeutic target as primary outcomes measures and the TTR percentages as second outcome measures. We will consider that achieve the therapeutic target is three INR's values within the therapeutic target. We will calculate the TTR in 4 and 12 weeks of follow-up.

\section{Sample size}

With a sample size of 150 patients for each arm separately, the study will have a power of $80 \%$ to observe a difference of $8 \%$ between TTR means of the TA and PA groups, using sigma of $25 \%$ and alpha of 0.05 .

\section{Randomization}

Patients will be randomized into two groups: TA group (traditional anticoagulation) and PA group (pharmacogenetic anticoagulation). The randomization method will be by original generator, which allowed for only one block size. We will use the randomization.com to perform the randomization automatically [35]. We will add two arms with 150 subjects each. Afterward, we will include the list of randomization on the REDCap. This web application choose automatically the arm according to the list of randomization in a way that the information can not be change.

\section{Blinding}

In this study, patients will be blinded and will not know their genetic results. The study team will not be blinded.

\section{Laboratorial measures and questionnaires}

Oral anticoagulant therapy will be assessed by the prothrombin time (PT) in an automated coagulometric method. Venous blood samples will be collected in tubes containing sodium citrate $3.8 \%$. INR calculation will be obtained by the ratio PT of the patient/normal PT controls, elevated to the international sensitivity index. Besides current INR, past INR values will be checked in electronic medical records. TTR will be calculated by the Rosendaal method [36], which uses linear interpolation to assign an INR value to each day between successive observed INR 
values. Peripheral venous blood will be collected into a BD Vacutainer System ${ }^{\bullet}$ without anticoagulant for measurements of serum creatinine, alanine aminotransferase (ALT), and aspartate aminotransferase (AST) by colorimetric and enzymatic assays.

Physicians and pharmacists will also complete a questionnaire for each patient. These will include the following variables: name, age, sex, body mass index, smoking, weekly intake of alcoholic beverages, weekly intake of dark green vegetables, comorbidities, results of last INR values, adverse events, and other drug use. In addition, the physician will evaluate the patients with the $\mathrm{CHADS}_{2} \mathrm{VASC}_{2}$ and HAS-BLED scores [37-39]. The $\mathrm{CHADS}_{2} \mathrm{VASC}_{2}$ score estimates stroke risk in patients with atrial fibrillation. The variables are congestive heart failure, hypertension, age $\geq 75$, diabetes mellitus, a history of stroke or transient ischemic attack symptoms and vascular disease history $[37,38]$. The HAS-BLED score estimates the risk of major bleeding for atrial fibrillation patients on anticoagulation care. "HAS-BLED" is an acronym for Hypertension (uncontrolled, systolic blood pressure $>160 \mathrm{mmHg}$ ), Abnormal liver (cirrhosis or bilirubin $>2 \mathrm{x}$ normal or AST/ALT/alkaline phosphatase $>3 \mathrm{x}$ normal) and renal function (dialysis, transplant, creatinine $>2.6 \mathrm{mg} / \mathrm{dL}$ ), Stroke history, Bleeding predisposition or Prior Major Bleeding, Labile INRs (unstable/high INRs or TTR $<60 \%$ ), Elderly (age $\geq 65$ ), Drugs (antiplatelet agents, nonsteroidal anti-inflammatory) or alcohol usage ( $\geq 8$ drinks/week) [39]. Each patient will have an individual record, which remains with the group of pharmacists and physicians. This record will provide information on current warfarin dose (mg/ week), daily dose, and INR values. Furthermore, each patient will have a card to register the warfarin daily dose.

The information gathered in the study will be managed using REDCap (Research Electronic Data Capture) tools hosted at the Clinical Hospital from the University of São Paulo Medical School. REDCap is a secure, webbased application designed to support data capture for research studies [40].

\section{Genotyping and predicted metabolic phenotypes}

We will collect blood samples using the BD Vacutainer System ${ }^{\circ}$ containing $\mathrm{K}_{3}$ EDTA (Becton Dickinson, USA). We will use the QIAamp DNA Blood Kit (QIAGEN, Hilden, Germany) to extract genomic DNA from peripheral blood leukocytes. Genotyping of CYP2C9*2 (c.430C > T, rs1799853), CYP2C9*3 (c.1075A >C, rs 1057910), and VKORC1 3673 (g.1639G > A, rs9923231) polymorphisms will be detected by real time PCR assays using Taqman probes (Applied Biosystems, CA, USA). We will use positive and negative reference samples to test along with the unknown samples in each run. TaqMan probe assay IDs: CYP2C9*2: C_25625805_10, CYP2C9*3: C_ 27104892_ 10, VKORC1 3673: C_30403261_20.
Patients will be divided into three distinct predicted phenotypes: extensive metabolizer (EM: wild-type genotypes for the CYP2C9 polymorphisms - *1/*1), intermediate metabolizer (IM: heterozygous genotypes for the loss-offunction CYP2C9 polymorphisms - " $1 /{ }^{*} 2$ or " $1 / * 3$ ) and poor metabolizer (PM: polymorphic homozygous or compound heterozygous genotypes for the loss-of-function CYP2C9 polymorphisms - *2/*2 or ${ }^{*} 3 / * 3$ or $\left.* 2 / * 3\right)[41,42]$.

\section{Pharmacogenetic algorithm}

The pharmacogenetic algorithm used in this clinical study was developed and validated by our group using two independent patient cohorts. It includes the variables age, sex, weight, height, self-declared race, use of amiodarone, use of enzyme inducers, VKORC1 genotypes, and predicted phenotypes according to CYP2C9 polymorphisms [21].

\section{Pharmacoeconomic analysis}

In these analyses we will evaluate the cost-effectiveness of both groups (TA and PA) calculating the costs of the genetic test, INR tests, and physician visits; and the effectiveness of the anticoagulation. We will also estimate costs that will be used to calculate the QALYs (qualityadjusted life year). These results that are used in QALYs are major bleeding, major thromboembolic events, and death. Major bleeding includes any episode of bleeding that requires hospitalization and thromboembolic events include embolic stroke, systemic embolism, ischemic attacks, deep venous thrombosis and pulmonary embolism.

\section{Statistical analysis}

Statistical analyses will be carried out using SPSS software (v. 16.0, IBM, New York, NY) and the level of significance set at $\mathrm{p} \leq 0.05$. Pharmacoeconomic data will be evaluated using the TreeAge software (TreeAge, Inc., Williamstown, MA). Chi-square tests will be performed for comparative analysis of the categorical variables (such as adverse events, and evaluation of percentage of INR within therapeutic range) according to the polymorphisms or with the two approaches that will be made (TA and PA). Students' $t$-tests or Mann-Whitney tests will be used for comparing TTR means and the time to achieve the therapeutic range according to the two groups. In addition, multivariate linear regression analysis will be used to identify variables associated with the TTR mean and with the time necessary to achieve the therapeutic range. A new randomization will not be performed for substitution of patients with missing data.

\section{Discussion}

This randomized study will include patients with low TTR from a cardiovascular tertiary hospital and it was designed to evaluate whether a population-specific genetic algorithm might be more effective than traditional 
anticoagulation for a selected group of poorly anticoagulated patients.

Previous clinical trials tested genetic-based algorithms in patients beginning warfarin therapy and found contrasting results [43]. However, no study to date has focused on this specific group of difficult to anticoagulate patients.

Our study has some potential limitations. First, although we will check the adverse effects during the study, we will not be able to analyze them with adequate statistical power. However, since these events may severely affect cost-effectiveness analysis they are contemplated in the study design. Second, we will use an algorithm modeled from a Brazilian cohort of patients and it will be applied in a specific group of patients of a tertiary referral hospital. Thus, applicability of our findings will need of external validity.

\section{Abbreviations}

ALT: Alanine aminotransferase; AST: Aspartate aminotransferase; CAPES: Coordenação de aperfeiçoamento de pessoal de nível superior; CNPQ: Conselho nacional de desenvolvimento científico e tecnológico; EM: Extensive metabolizer; FAPESP: Fundação de amparo à pesquisa do estado de São Paulo; IM: Intermediate metabolizer; INR: International normalized ratio; PA: Pharmacogenetic anticoagulation; PM: Poor metabolizer; PT: Prothrombin time; QALYs: Quality-adjusted life year; REDCap: Research electronic data capture; TA: Tradicional anticoagulation; TTR: Time in the therapeutic range

\section{Acknowledgements}

FAPESP, CAPES and CNPQ for financial support and Farmoquímica S.A for drug donate.

\section{Funding}

This project is funded by the FAPESP, Proc. 2013/09295-3 and CNPQ, Proc. 440324/2014-9.

\section{Availability of data and materials}

We do not wish to share our data because more clinical variable will be studied.

\section{Authors' contribution}

All authors read and approved the final manuscript. LRM, LS, CMCS, FCCD, MIS, JEK, ACP and PCJLS drafted the study protocol and participated in the design of the study. LRM, CTB, LS, MF and PCJLS will select the patients and will collect data from patients. LS, MF and FCCD will adjust the dose. LRM, CTB will carry out the genetic tests, will do the pharmaceutical care, and will follow the patient. PCJLS will do the statistical analysis and will coordinate the study. CMCS will do the laboratorial tests.

\section{Authors' information}

LRM is a Master Degree student in a Graduate Studies Program in Health Sciences, University of São Paulo Medical School.

LS and CTB is a PhD student in a Graduate Studies Program in Health Sciences, University of São Paulo Medical School.

MF is a cardiologist at Heart Institute.

FCCD, MIS, JEK, ACP PhD is a cardiologist at Heart Institute.

CMCS PhD is a director of the clinical laboratory at Heart Institute.

PCJLS PhD is a researcher.

\section{Competing interests}

The authors declare that they have no competing interests.

\section{Consent for publication}

Not applicable. All patients signed a consent term.

\section{Ethical approval and consent to participate}

The study protocol was approved by the Ethics Committee for Medical Research on Human Beings of the Clinical Hospital of the University of São Paulo Medical School (SDC 4033/14/013). Signed informed consent will be obtained from all participants.

\section{Registration}

Current Controlled Trials number: NCT02592980 named by Evaluation of a Pharmacogenetic-based Warfarin Dosing Algorithm in Patients.

\section{Author details}

${ }^{1}$ Laboratory of Genetics and Molecular Cardiology, Heart Institute (InCor), University of São Paulo Medical School, Av. Dr. Eneas de Carvalho Aguiar, 44 Cerqueira Cesar, São Paulo, SP CEP 05403-000, Brazil. ²Arrhythmia Unit, Heart Institute (InCor), University of São Paulo Medical School, Av. Dr. Eneas de Carvalho Aguiar, 44 Cerqueira Cesar, São Paulo, SP CEP 05403-000, Brazil. ${ }^{3}$ Clinical Laboratory, Heart Institute (InCor), University of São Paulo Medical School, Av. Dr. Eneas de Carvalho Aguiar, 44 Cerqueira Cesar, São Paulo, SP CEP 05403-000, Brazil.

Received: 7 September 2016 Accepted: 8 November 2016

Published online: 17 November 2016

\section{References}

1. Stehle S, Kirchheiner J, Lazar A, Fuhr U. Pharmacogenetics of oral anticoagulants: a basis for dose individualization. Clin Pharmacokinet. 2008:47:565-94.

2. Lind M, Fahlen M, Kosiborod M, Eliasson B, Oden A. Variability of INR and its relationship with mortality, stroke, bleeding and hospitalisations in patients with atrial fibrillation. Thromb Res. 2012;129:32-5.

3. Ageno W, Gallus AS, Wittkowsky A, Crowther M, Hylek EM, Palareti G. Oral anticoagulant therapy: Antithrombotic Therapy and Prevention of Thrombosis, 9th ed: American College of Chest Physicians Evidence-Based Clinical Practice Guidelines. Chest. 2012;141:e44S-88.

4. Singer DE, Hellkamp AS, Piccini JP, Mahaffey KW, Lokhnygina Y, Pan G, Halperin JL, Becker RC, Breithardt G, Hankey GJ, et al. Impact of global geographic region on time in therapeutic range on warfarin anticoagulant therapy: data from the ROCKET AF clinical trial. J Am Heart Assoc. 2013;2, e000067.

5. Caldeira D, Cruz I, Morgado G, Stuart B, Gomes C, Martins C, Joao I, Pereira $\mathrm{H}$. Evaluation of time in therapeutic range in anticoagulated patients: a single-center, retrospective, observational study. BMC Res Notes. 2014;7:891.

6. Rose AJ, Hylek EM, Ozonoff A, Ash AS, Reisman JI, Berlowitz DR. Risk-adjusted percent time in therapeutic range as a quality indicator for outpatient oral anticoagulation: results of the Veterans Affairs Study to Improve Anticoagulation (VARIA). Circ Cardiovasc Qual Outcomes. 2011:4:22-9.

7. White HD, Gruber M, Feyzi J, Kaatz S, Tse HF, Husted S, Albers GW. Comparison of outcomes among patients randomized to warfarin therapy according to anticoagulant control: results from SPORTIF III and V. Arch Intern Med. 2007;167:239-45.

8. Holbrook A, Schulman S, Witt DM, Vandvik PO, Fish J, Kovacs MJ, Svensson PJ, Veenstra DL, Crowther M, Guyatt GH. Evidence-based management of anticoagulant therapy: Antithrombotic Therapy and Prevention of Thrombosis, 9th ed: American College of Chest Physicians Evidence-Based Clinical Practice Guidelines. Chest. 2012;141:e152S-84.

9. Nasser S, Mullan J, Bajorek B. Challenges of older patients' knowledge about warfarin therapy. J Prim Care Community Health. 2012;3:65-74.

10. Rose AJ, Hylek EM, Ozonoff A, Ash AS, Reisman Jl, Berlowitz DR. Patient characteristics associated with oral anticoagulation control: results of the Veterans AffaiRs Study to Improve Anticoagulation (VARIA). J Thromb Haemost. 2010;8:2182-91.

11. Oramasionwu CU, Bailey SC, Duffey KE, Shilliday BB, Brown LC, Denslow SA, Michalets EL. The association of health literacy with time in therapeutic range for patients on warfarin therapy. J Health Commun. 2014;19 Suppl 2:19-28.

12. Bhandari VK, Wang F, Bindman AB, Schillinger D. Quality of anticoagulation control: do race and language matter? J Health Care Poor Underserved. 2008;19:41-55.

13. Shen AY, Yao JF, Brar SS, Jorgensen MB, Wang X, Chen W. Racial/Ethnic differences in ischemic stroke rates and the efficacy of warfarin among patients with atrial fibrillation. Stroke. 2008;39:2736-43. 
14. Nieuwlaat R, Connolly BJ, Hubers LM, Cuddy SM, Eikelboom JW, Yusuf S, Connolly SJ. Quality of individual INR control and the risk of stroke and bleeding events in atrial fibrillation patients: a nested case control analysis of the ACTIVE W study. Thromb Res. 2012;129:715-9.

15. Takahashi H, Wilkinson GR, Padrini R, Echizen H. CYP2C9 and oral anticoagulation therapy with acenocoumarol and warfarin. similarities yet differences. Clin Pharmacol Ther. 2004;75:376-80.

16. Pirmohamed $M$, Burnside $G$, Eriksson $N$, Jorgensen $A L$, Toh $C H$, Nicholson $T$, Kesteven P, Christersson C, Wahlstrom B, Stafberg C, et al. A randomized trial of genotype-guided dosing of warfarin. N Engl J Med. 2013;369:2294-303.

17. Van Schie RM, Wessels JA, le Cessie S, de Boer A, Schalekamp T, van der Meer FJ, Verhoef TI, van Meegen E, Rosendaal FR, Maitland-van der Zee AH. Loading and maintenance dose algorithms for phenprocoumon and acenocoumarol using patient characteristics and pharmacogenetic data. Eur Heart J. 2011:32:1909-17.

18. Verhoef TI, Ragia G, de Boer A, Barallon R, Kolovou G, Kolovou V, Konstantinides S, Le Cessie S, Maltezos E, van der Meer FJ, et al. A randomized trial of genotype-guided dosing of acenocoumarol and phenprocoumon. N Engl J Med. 2013;369:2304-12.

19. Gage BF, Eby C, Johnson JA, Deych E, Rieder MJ, Ridker PM, Milligan PE, Grice $G$, Lenzini $P$, Rettie $A E$, et al. Use of pharmacogenetic and clinical factors to predict the therapeutic dose of warfarin. Clin Pharmacol Ther. 2008;84:326-31.

20. Kimmel SE, French B, Kasner SE, Johnson JA, Anderson JL, Gage BF, Rosenberg YD, Eby CS, Madigan RA, McBane RB, et al. A pharmacogenetic versus a clinical algorithm for warfarin dosing. N Engl J Med. 2013;369:2283-93.

21. Santos PC, Marcatto LR, Duarte NE, Soares RA, Strunz CM, Scanavacca M, Krieger JE, Pereira AC. Development of a pharmacogenetic-based warfarin dosing algorithm and its performance in Brazilian patients: highlighting the importance of population-specific calibration. Pharmacogenomics. 2015;16(8):1-12

22. Pavani A, Naushad SM, Rupasree Y, Kumar TR, Malempati AR, Pinjala RK, Mishra RC, Kutala VK. Optimization of warfarin dose by population-specific pharmacogenomic algorithm. Pharmacogenomics J. 2012;12:306-11.

23. Ekladious SM, Issac MS, El-Atty Sharaf SA, Abou-Youssef HS. Validation of a proposed warfarin dosing algorithm based on the genetic make-up of Egyptian patients. Mol Diagn Ther. 2013;17:381-90.

24. Cho HJ, On YK, Bang OY, Kim JW, Huh W, Ko JW, Kim JS, Lee SY. Development and comparison of a warfarin-dosing algorithm for Korean patients with atrial fibrillation. Clin Ther. 2011;33:1371-80.

25. Young S, Bishop L, Twells L, Dillon C, Hawboldt J, O'Shea P. Comparison of pharmacist managed anticoagulation with usual medical care in a family medicine clinic. BMC Fam Pract. 2011;12:88.

26. Clarkesmith DE, Pattison HM, Lip GY, Lane DA. Educational intervention improves anticoagulation control in atrial fibrillation patients: the TREAT randomised trial. PLoS One. 2013;8, e74037.

27. Okuyama $Y$, Matsuo $M$, Matsuo $H$, Sakaguchi $Y$, Takai $H$, Horiguchi $Y$, Ryomoto T, Adachi S, Amano T, Togawa M, et al. Introduction of point-of-care testing in Japanese outpatient clinics is associated with improvement in time in therapeutic range in anticoagulant-treated patients. Circ J. 2014;78:1342-8.

28. Leey JA, McCabe S, Koch JA, Miles TP. Cost-effectiveness of genotypeguided warfarin therapy for anticoagulation in elderly patients with atrial fibrillation. Am J Geriatr Pharmacother. 2009;7:197-203.

29. Chong HY, Saokaew S, Dumrongprat K, Permsuwan U, Wu DB, Sritara P, Chaiyakunapruk N. Cost-effectiveness analysis of pharmacogenetic-guided warfarin dosing in Thailand. Thromb Res. 2014;134:1278-84.

30. Eckman MH, Rosand J, Greenberg SM, Gage BF. Cost-effectiveness of using pharmacogenetic information in warfarin dosing for patients with nonvalvular atrial fibrillation. Ann Intern Med. 2009;150:73-83.

31. Ansell J, Hirsh J, Hylek E, Jacobson A, Crowther M, Palareti G. Pharmacology and management of the vitamin K antagonists: American College of Chest Physicians Evidence-Based Clinical Practice Guidelines (8th Edition). Chest. 2008;133:160S-98.

32. Cushman M, Lim W, Zakai N. 2011 Clinical Practice Guide on Anticoagulant Dosing and Management of Anticoagulant Associated Bleeding Complications in Adults. Washington: American Society of Hematology (8th Edition); 2011.

33. Guyatt GH, Akl EA, Crowther M, Gutterman DD, Schuunemann HJ. Executive summary: antithrombotic therapy and prevention of thrombosis, 9th ed: American College of Chest Physicians Evidence-Based Clinical Practice Guidelines. Chest. 2012;141:7S-47.
34. Horton JD, Bushwick BM. Warfarin therapy: evolving strategies in anticoagulation. Am Fam Physician. 1999:59:635-46.

35. Dallal GE. Randomization.com. 2008. http://randomization.com/. Accessed 10 Sept 2015.

36. Rosendaal FR, Cannegieter SC, van der Meer FJ, Briet E. A method to determine the optimal intensity of oral anticoagulant therapy. Thromb Haemost. 1993;69:236-9.

37. Gage BF, Waterman AD, Shannon W, Boechler M, Rich MW, Radford MJ. Validation of clinical classification schemes for predicting stroke: results from the National Registry of Atrial Fibrillation. JAMA. 2001;285:2864-70.

38. Lip GY, Nieuwlaat R, Pisters R, Lane DA, Crijns HJ. Refining clinical risk stratification for predicting stroke and thromboembolism in atrial fibrillation using a novel risk factor-based approach: the euro heart survey on atrial fibrillation. Chest. 2010;137:263-72.

39. Pisters R, Lane DA, Nieuwlaat R, de Vos CB, Crijns HJ, Lip GY. A novel userfriendly score (HAS-BLED) to assess 1-year risk of major bleeding in patients with atrial fibrillation: the Euro Heart Survey. Chest. 2010;138:1093-100.

40. Harris PA, Taylor R, Thielke R, Payne J, Gonzalez N, Conde JG. Research electronic data capture (REDCap)-a metadata-driven methodology and workflow process for providing translational research informatics support. J Biomed Inform. 2009:42:377-81.

41. Soares RA, Santos PC, Machado-Coelho GL, Nascimento RM, Mill JG, Krieger JE, Pereira AC. CYP2C9 and VKORC1 polymorphisms Are differently distributed in the Brazilian population according to self-declared ethnicity or genetic ancestry. Genet Test Mol Biomarkers. 2012;16:957-63.

42. Santos PC, Dinardo CL, Schettert IT, Soares RA, Kawabata-Yoshihara L, Bensenor IM, Krieger JE, Lotufo PA, Pereira AC. CYP2C9 and VKORC1 polymorphisms influence warfarin dose variability in patients on long-term anticoagulation. Eur J Clin Pharmacol. 2013;69(4):789-97.

43. Zineh I, Pacanowski M, Woodcock J. Pharmacogenetics and coumarin dosing-recalibrating expectations. N Engl J Med. 2013;369:2273-5.

\section{Submit your next manuscript to BioMed Central and we will help you at every step:}

- We accept pre-submission inquiries

- Our selector tool helps you to find the most relevant journal

- We provide round the clock customer support

- Convenient online submission

- Thorough peer review

- Inclusion in PubMed and all major indexing services

- Maximum visibility for your research

Submit your manuscript at www.biomedcentral.com/submit
) Biomed Central 